Research Article

\title{
Effect of Squalene in Morphometric and Cognitive Aspects in D-Galactose induced Alzheimers Disease in Male Albino Rats
}

\author{
Kukkarasapalli Praveen, Kuna Yellamma* \\ Department of Zoology, Sri Venkateswara University, Tirupati, Andhra Pradesh, India. 517502. \\ *Corresponding author's E-mail: yellamma55@gmail.com
}

Received: 21-07-2021; Revised: 28-09-2021; Accepted: 06-10-2021; Published on: 15-10-2021.

ABSTRACT

Alzheimers disease is a type of dementia, even though extensive research work has been carried out since decades till now, there is no specific therapeutic drug available for the permanent cure of the Alzheimer's Disease. Now a days the marine bioactive compound squalene plays a therapeutic role morphometric and cognitive aspects in D-Galactose induced alzheimers disease in male albino rats. The morphometric aspects which refer to the quantitative analysis of a concept that encompasses size, shape and other physical parameters is useful for assessing the impact of mutants on shape, their fossil records, developmental changes in the form between ecological factors and as well as evaluating the quantitative genetic aspects of shape. To evaluate the spatial or place learning in experimental rat, the most popularly known water maze test is Morris Water Maze (MWM) experiment. The most important utilization of the Morris Water Maze includes that its high reliability across a wide range of tank configurations and testing procedures, its cross-species utility in several chosen experimental animals such as mice and rats including humans in a virtual maze. The marine bioactive compound Squalene plays a major impact on brain function and behaviour by enhancing the learning and memory in the AD- Model rats.

Keywords: Alzheimers Disease (AD), Marine bioactive compound Squalene, Morris Water Maze (MWM) and D-Galactose.

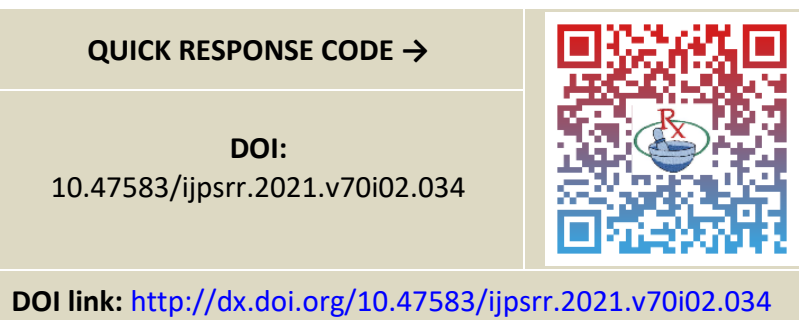

\section{INTRODUCTION}

Izheimers disease $(A D)$ is the most common single cause of dementia in our ageing society. $A D$ is estimated to account for between 50 and $60 \%$ of dementia cases in persons over 65 years of age ${ }^{1-3}$ and is progressive, neurodegenerative disease that primarily affects the elderly population. The symptoms associated with $A D$ involve decline in cognitive dysfunction, primarily memory loss 4,5 and in the later stages of the disease language deficits, depression, agitation, mood disturbances and psychosis are often seen ${ }^{6 .}$

It is a multifactorial illness, mainly related to oxidative stress leading to the inequity between production and detoxification of Reactive Oxygen Species (ROS), a chief issue for developments of neurodegenerative diseases ${ }^{7}$. Oceans account for $71 \%$ of the earth's surface and are the largest remaining reservoirs of bioactive compounds ${ }^{8}$. Consequently, through the past decade, the Neuro protective properties of diverse compounds from Squalene have been investigated in neurodegenerative diseases, such as Alzheimer's (AD) and Parkinson's (PD) ${ }^{9}$.

\section{Morphometric Aspects}

Morphometric $^{10}$ studies play a significant role in understanding many biological functions. Further, the major advantages of morphological measurements have wide applications in creating phylogenetic relationships ${ }^{11}$, sexual dimorphism ${ }^{12}$, evolution ${ }^{13}$, body condition ${ }^{14}$, Eco morphology ${ }^{15}$, heritability ${ }^{16}$ and growth ${ }^{17}$. Thus, the major objective of the marphometrics is to statistically test hypothesis about the factors that affect shape. In the wider sense, it is also used to locate precisely certain areas of featureless organs such as brain and is used in describing the shape of other organs.

The traditional morphometric information is nevertheless useful when either absolute or relative sizes are of particular interest such as in studies of growth. Besides this, it is also useful for measurement of size of theoretical importance such as body weight and limb cross-sectional area and length in studies of functional morphology. However, all these measurements have one important limitation i.e. they contain little information about the spatial distribution of shape changes across the organism. Several studies conducted by researchers highlighted the importance of these studies: For example the study conducted by 18 to determine variability in body morphometric measurements in goats of Uganda, concluded that live body weight could be predicted with accuracy from linear body measurements especially in height at wither, heart girth, corpus length and ramp height. The body, carcass weights and chest circle would be determined more efficiently by measuring the width of long bones in Morkara man sheep ${ }^{19-20}$. It is also been 
reported that there isa positive correlation between body weight and Linear Body Measurements in Chinchilla rabbits implying that a particular Linear Body Measurements or a combination of it can be used to determine the body weight.

\section{Cognitive Aspects}

The practice of Morris Water Maze in assessing learning and memory has been reviewed ${ }^{21-22}$ as the relationship between performance in the Morris Water Maze and both neurotramitter systems and drug effects ${ }^{23}$. The Morris Water Maze concert has been linked to Long- Term Potentiation and NMDA receptor function ${ }^{24}$, making it a key technique in the investigation of hippocampal circuitry.

Hence, the locomotory activity is considered as an index of alertness and a decrease in the activity would indicate the sedative state of the animal. The locomotor activity is one of the most widely used behavioral paradigms to determine the effects of various experimental manipulations ranging from genetic changes, knockout mice to pharmacological challenges. Thisextensive range of applications is based on the fact that unconditioned motor activity probes a variety of behaviours that can be recorded automatically and quickly generate and effect profile ${ }^{25}$.The multivariate characterizations of rat locomotory activity, including measures of crossings, time in the centre vs. the periphery, distance travelled, rearing and sometimes whole pokes, having many advantages over univariate assessments are limited to measures of theamount of activity ${ }^{26}$. However, studies in rats also clearly confirmed the additional utility of assessments of sequential patterns of locomotor activity in pharmacological and neurobiological studies. The maximum drugs acting on the Central Nervous System in general and the depressant drugs such as barbiturates and alcohol influence the locomotor activities by reducing the motor activity, though the stimulants such as caffeine and amphetamines increase the activity in man and animals.

The laboratory rats have proved as valuable animal models in psychological studies such as learning and other mental processes. The ancient significance of this species to scientific research is reflected by the amount of literature on it, unevenly $50 \%$ more than that on other animals ${ }^{27}$. It has been well established that the water maze performance declines with ageing of animals and it is a very sensitive method for evaluating the impairment of spatial learning and memory. The water maze studies help to reveal general principles about learning that can be useful to many species, including humans. Water mazes are also used to determine whether different treatments or conditions affect memory and learning in rats. The rats having the maze running capability comes from their inheritance through evolution, as rats are small burrowing rodents that have spent millennia in digging and finding their way in and around underground tunnels. The maze apparatus are useful for assessment of memory with little effort. The T-maze tests have been used to assess the spatial learning behaviour of animals. Some previous studies have confirmed that spatial and non-spatial cognition are two important aspects of cognitive function 28. The locomotor abnormalities are associated with several human diseases like Parkinson's, Huntington's and Hyperactivity syndrome. The marine bioactive compound like shark liver oil, Squalene plays a major impact on brain function and behaviour by mainly controlling the presqualene and post-squalene pathway in the brain lipid molecules.

\section{MATERIALS AND METHODS}

Healthy male albino rats (48) of wistar strain were divided into four groups viz., Group-I: control rats received saline, Group-II: rats received intraperitoneal injection of DGalactose $(120 \mathrm{mg} / \mathrm{kg}$ body weight) throughout experiment, Group-III: initially animals were subjected to D-Galactose injection for six weeks, then followed by simultaneously received both

D-Galactose and Squalene (150 mg/kg body weight) for 90 days and GroupIV: rats which were orally administered only with Squalene for 90 days. During the experimentation, both morphometric and behavioural aspects were studied in selected brain regions of all experimental groups of rats on selected days of experimentation $\left(60^{\text {th }}\right.$ and $90^{\text {th }}$ days).

\section{Statistical analysis}

All the experiments were carried out in triplicates and values of the measured parameters were expressed as Mean \pm SEM. Two way ANOVA was used to test the significance of difference among nine different groups followed by Dunnet's Multiple Range Test (DMRT). Statistical analysis was performed by using Statistical Program of Social Sciences (SPSS) for windows (Version 16; SPSS Inc., Chicago, 1L, USA). The data was regarded as significantly different at $\mathrm{P}<0.05$.

\section{RESULTS}

\section{Morphological features}

The morphological topographies such as Body weight, general appearance, and organ indexwere recorded in all groups of rats during the total experimentation period. From these results, it was observed that when compared to Control group rats, AD model rats showed gradual loss of hair, elasticity of the skin which later became stiff, thin and saggy. Besides these, significant andgradual reduction in the body weight by $18.4 \%$ on $60^{\text {th }}$ day and $26.73 \%$ on $90^{\text {th }}$ day was also recorded with reference to the control group. The control group, and Squalene alone treated groups have exhibited a similar trend. On the contrary, the protective group of rats (ADI+SQT), which were treated with Squalene for 60 and 90 days exhibited increase in their body weights when compared to Alzheimer's Diseased model group (318.21 \pm 0.88 vs. $261.84 \pm 18.44$ and $331.12 \pm 3.13$ vs. $235.22 \pm 26.73$ ) respectively. In parallel to these parameters, the organ index of selected organs such as Brain, Liver, Kidney and Spleen, also showed 
significant weakening in the AD-model group when compared to that of squalene treated group. However, interestingly, the organ index in protective group exhibited better gain in organ weight than that of $A D$ - model group.

\section{Cognitive behaviour}

The modulatory effects of squalene on spatial memory (wherein the escape latency was taken as an index of impairment of cognitive function) were studied by Morris water maze experiment. The results showed that,
Squalene alone treated rats have showed better escape latency on selected days of experiment, when compared to control rats. On the contrary, the rats treated with DGalactose alone showed a significant enhancement in the escape latency time on $60^{\text {th }}$ day $(70.97 \%)$ and $90^{\text {th }}$ day $(133.48 \%)$. Interestingly, the protective group of rats (ADI+SQT), showed better recovery tendency with reduced latency on $60^{\text {th }}$ day $(8.89 \%)$ and $90^{\text {th }}$ day $(-10.85 \%)$ and it was almost very close to that of the control group rats.

Table 1: Changes in Organ index for selected organs from different groups of rats on $60^{\text {th }}$ and $90^{\text {th }}$ days of Experimentation.

\begin{tabular}{|c|c|c|c|c|c|c|c|c|}
\hline \multirow{2}{*}{$\begin{array}{l}\text { Name of organ } \\
\text { Selected days }\end{array}$} & \multicolumn{2}{|c|}{ Brain } & \multicolumn{2}{|c|}{ Kidney } & \multicolumn{2}{|c|}{ Liver } & \multicolumn{2}{|c|}{ Spleen } \\
\hline & $60^{\text {th }}$ & $90^{\text {th }}$ & $60^{\text {th }}$ & $90^{\text {th }}$ & $60^{\text {th }}$ & $90^{\text {th }}$ & $60^{\text {th }}$ & $90^{\text {th }}$ \\
\hline \multicolumn{9}{|l|}{ Group } \\
\hline \multirow{2}{*}{ Control } & 1.90 & 2.03 & 2.01 & 2.05 & 9.41 & 10.06 & 1.32 & 1.27 \\
\hline & \pm 0.4 & \pm 0.10 & \pm 0.22 & \pm 0.11 & \pm 0.63 & \pm 1.25 & \pm 0.17 & \pm 0.27 \\
\hline \multirow{2}{*}{ SQ-T } & 1.83 & 1.92 & 4.07 & 5.35 & 8.66 & 9.02 & 1.45 & 1.24 \\
\hline & \pm 0.05 & \pm 0.19 & \pm 0.31 & \pm 0.75 & \pm 0.68 & \pm 0.97 & \pm 0.27 & \pm 0.25 \\
\hline \multirow{2}{*}{ AD-I } & 1.78 & 1.84 & 2.98 & 4.52 & 8.26 & 9.57 & 0.92 & 1.28 \\
\hline & \pm 0.16 & \pm 0.18 & \pm 0.80 & \pm 0.25 & \pm 0.82 & \pm 3.09 & \pm 0.19 & \pm 0.31 \\
\hline \multirow{2}{*}{$\begin{array}{l}\text { Protective Group } \\
\qquad \text { (ADI+SQT) }\end{array}$} & 2.05 & 1.95 & 1.90 & 2.46 & 8.67 & 10.32 & 1.46 & 1.69 \\
\hline & \pm 0.25 & \pm 0.30 & \pm 0.18 & \pm 0.37 & \pm 0.69 & \pm 1.69 & \pm 0.27 & \pm 0.60 \\
\hline
\end{tabular}

(Note: The above values are expressed in grams)

Table 2: Differences in total body weights (Grams) of Control and Experimental groups of rats on selected days of experimentation.

\begin{tabular}{|c|c|c|}
\hline Group & $\mathbf{6 0}^{\text {th }}$ day & $\mathbf{9 0}^{\text {th }}$ day \\
\hline Control & $321.04 \pm 28.90$ & $340.31 \pm 68.24$ \\
\hline SQ-T & $292.23 \pm 16.71(-8.97)$ & $332.12 \pm 64.00(3.45)$ \\
\hline AD-I & $261.84 \pm 21.53(-18.44)$ & $235.22 \pm 16.78(-26.73)$ \\
\hline ADI+SQT & $318.21 \pm 60.32(-0.88)$ & $331.12 \pm 58.17(3.13)$ \\
\hline
\end{tabular}

Values are Mean \pm SEM of six observations pooled from 6 rats.; Values in parentheses are percent changes from control $\left(\right.$ Except $\left.{ }^{*}\right) ;$ *Values in parentheses are percent changes from AD-induced rats;

Values are significantly different from control at $p<0.05$

Table 3: ANOVA

\begin{tabular}{|c|c|c|c|c|c|c|}
\hline \multicolumn{2}{|c|}{ Body weight } & Sum of squares & Df & Mean Square & $\mathbf{F}$ & Sig. \\
\hline \multirow{3}{*}{ On $60^{\text {th }}$ day } & Between Group & 13679.054 & 3 & 4559.685 & 11.569 & 0.000 \\
\hline & Within group & 7882.859 & 20 & 394.143 & & \\
\hline & Total & 21561.914 & 23 & & & \\
\hline \multirow{3}{*}{ On $90^{\text {th }}$ day } & Between Group & 44678.966 & 3 & 14892.989 & 34.870 & 0.000 \\
\hline & Within group & 8542.118 & 20 & 427.106 & & \\
\hline & Total & 53221.084 & 23 & & & \\
\hline
\end{tabular}


Graph-1: Effect of squalene on total body weight of control and experimental groups of rats on selected days of experimentation. Values are mean $\pm \operatorname{SEM}(n=6)$. ${ }^{*} p<0.01$ vs. Control; $\# p<0.05$ vs. AD model group.

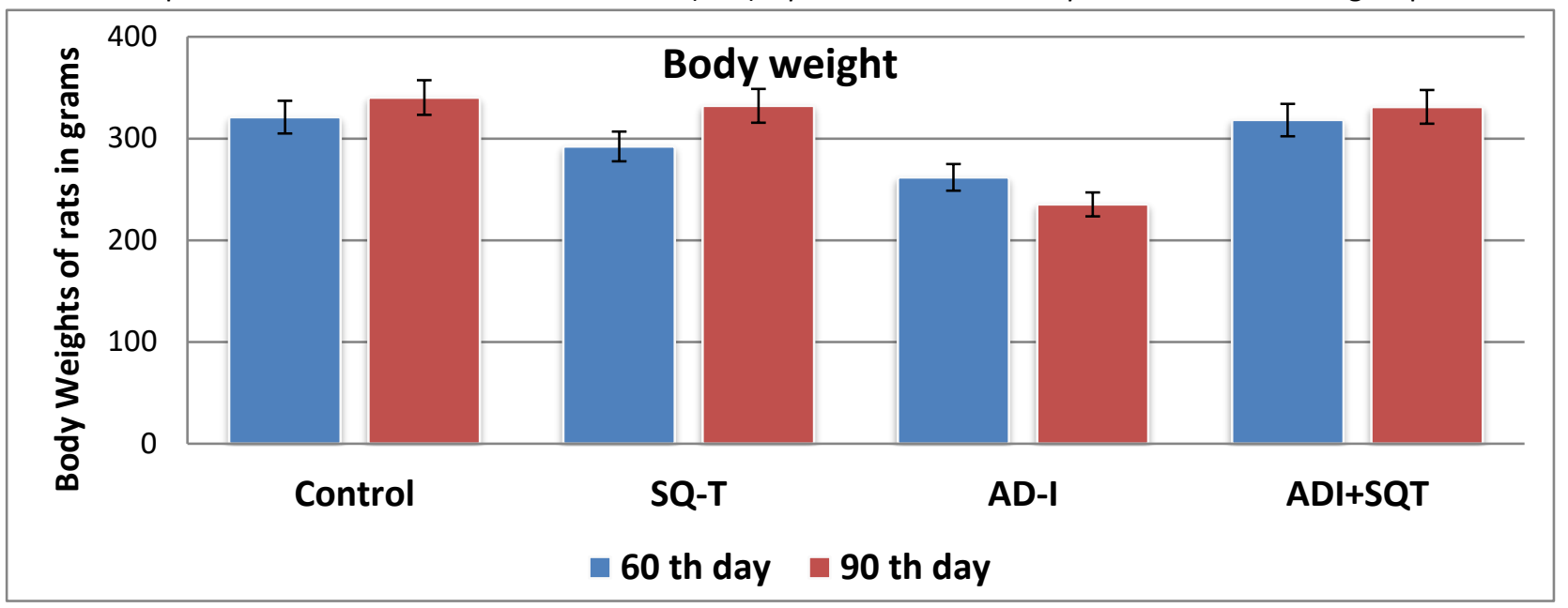

Table 4: Alterations in the Cognitive performance of Control and Experimental group of rats on selected days of experimentation.

\begin{tabular}{|c|c|c|}
\hline Group & $\mathbf{6 0}^{\text {th }}$ day & $\mathbf{9 0}^{\text {th }}$ day \\
\hline Control & $13.16 \pm 1.34$ & $12.99 \pm 0.57$ \\
\hline SQ-T & $12.33 \pm 0.74(-6.30)$ & $10.58 \pm 0.60(-18.55)$ \\
\hline AD-I & $22.5 \pm 3.09(70.97)$ & $30.33 \pm 1.88(133.48)$ \\
\hline ADI + SQT & $14.33 \pm 0.47(8.89)$ & $11.58 \pm 0.73(-10.85)$ \\
\hline
\end{tabular}

Values are Mean \pm SEM of six observations pooled from 6 rats.; Values in parentheses are percent changes from control (Except *); *Values in parentheses are percent changes from AD- rats;

Values are significantly different from control at $p<0.05$

Table 5: ANOVA

\begin{tabular}{|c|c|c|c|c|c|c|}
\hline \multicolumn{2}{|c|}{ Morris Maze Test } & Sum of squares & Df & Mean Square & $\mathbf{F}$ & Sig. \\
\hline \multirow{3}{*}{ On $60^{\text {th }}$ day } & Between Group & 394.833 & 3 & 131.611 & 36.058 & 0.000 \\
\hline & Within group & 73.000 & 20 & 3.650 & & \\
\hline & Total & 467.833 & 23 & & & \\
\hline \multirow{3}{*}{ On $90^{\text {th }}$ day } & Between Group & 1565.833 & 3 & 521.944 & 347.963 & 0.000 \\
\hline & Within group & 30.000 & 20 & 1.500 & & \\
\hline & Total & 1595.833 & 23 & & & \\
\hline
\end{tabular}

Graph 2: Effect of squalene on cognitive performance in different groups of experimental rats against the Control on selected days. Values are mean $\pm \operatorname{SEM}(n=6) .{ }^{*} p<0.05 v$ s. Control; $\# p<0.05$ vs. AD model group. 40

\section{Morris water Maze}
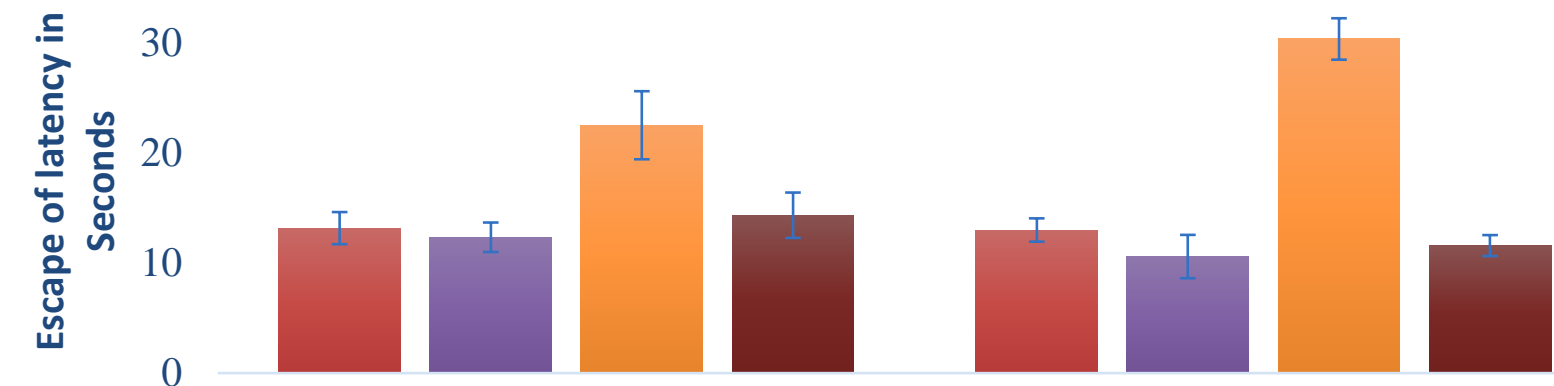

60 th Day

Experimental groups

90 th day

$\square$ Control $\square$ SQ-T $\quad$ AD-I $\quad$ ADI + SQT 


\section{DISCUSSION}

The present findings in my study clearly indicated that the marine compound, squalene showed positive modulatory effects against the experimentally induced changes due to Alzheimer's Disease which are reflected in behavioraland morphometric aspects. Throughout the period of experimentation, the AD-model rats show a significant decline in their organ index, cognitive skills, total body weight, loss of hair and elasticity of the skin. Besides these, Alzheimer's Disease-induced rats showed deficiency in memory and learning. However, oral administration of Squalene significantly reversed not only the morphological parameters but also the memory impairment caused by ADinduction, indicating that Squalene acted as Anti-Alzheimer compound.

Squalene is an intermediate compound in the cholesterol biosynthesis having antioxidant and membrane stabilizing property. The marine bioactive compounds play important roles in development of functional foods and drugs based on their Antitumor, Antimicrobial, Antioxidant and other properties. The Pharmacological studies with marine compounds involve areas of neuropharmacology, such as those of stimulation of neurogenesis, modulation of receptors and voltage-dependent ion channels and enzymes inhibition ${ }^{29}$, that correct several neurological disorders. Therefore, several research studies have emerged which could explain that the potential mechanism of action and the direct stimulation of cytokine and chemokine production by granulocytes and macrophages 30. In rat model, oral administration of squalene was absorbed by lymphatic vessels like cholesterol with only $20 \%$ becoming sterols during transmit through the small intestine. Its consumption also reduce cholesterol, LDL cholesterol and triglyceride levels after 20 weeks with Squalene treatment. Other in vivo studies, have demonstrated that administration of a dose of $2 \%$ of squalene for 45 days could significantly reduced the levels of triglycerides, cholesterol and fatty acids in plasma and heart tissues thus confirming the cardio protective effects of Squalene has a nonpolar nature that allows to function as a purifier of xenobiotic substances in the human body.

The observation that squalene has reversed the $A D$ induced effects with reference to the locomotor behaviour can be justified with a supporting mechanism explaining the role of Calcium and its associated enzyme viz. $\mathrm{Ca}^{2+}$ ATPase. The transport of $\mathrm{Ca}^{2+}$ across the Sarcoplasmic reticulum membrane by Sarco-Endoplasmic Reticulum $\mathrm{Ca}^{2+}$ ATPases (SERCA) can be controlled by the regulatory protein, phospholamban (PLB). In normal condition the SERCA is inhibited by PLB and is closely associated with it. The increased $\beta$-adrenergic stimulation reduces the association between SERCA and PLB by Protein kinase. When Phospholamban is associated with Sarco-Endoplasmic Reticulum $\mathrm{Ca}^{2+}$ ATPases, it leads to reduction of $\mathrm{Ca}^{2+}$ movement whereas dissociation of phospholamban with SERCA, results in increased $\mathrm{Ca}^{2+}$ movement. The sarcoplasmic reticulum has a much higher concentration of
$\mathrm{Ca}^{2+}$ inside when compared to the cytoplasmic $\mathrm{Ca}^{2+}$ concentration. In view of the above results, it is understood further that the effect of squalene can be comparable with several compounds of plant origin which lend strong support to our findings. To cite a few: Chronic injection of D-Galactose induced memory impairment, oxidative damage in mice followed by neurodegeneration ${ }^{31}$, Chronic administration of D-Galactose caused significant decline in reduced gross behavioral activity and spatial memory suggesting impairment of memory ${ }^{32}$, It was demonstrated that ethanol extract of Bacopa monniera has effectively reversed the D-Galactose-induced memory impairment and learning.

The comparative studies conducted in the present study on the above aspects on $60^{\text {th }}$ and $90^{\text {th }}$ day treated rats, it was obvious that chronic administration of Squalene for 60 days and $90^{\text {th }}$ day showed significant improvement and recovery from Alzheimer's Disease effects which was dependent on the duration of Alzheimer's Disease induction and also treatment of $A D$-induced rats with marine bioactive compound Squalene. As the treatment days of rats with Squalene increased, the amount of memory gaining was also improved. Our research finding further proved that oral administration of squalene extended positive effect on the memory aspects ofrat. The squalene has the ability to produce neurochemicals that are exactly analogues in structure those produced by the host nervous system and act as vehicles for neurotransmitters and influence the mood and behaviour ${ }^{33}$.

From these results, it is observed that when compared to Control group rats, AD model ratsshowed gradual loss of hair, elasticity of the skin which later became stiff, thin and saggy. Besides these, significant and gradual reduction in the body weight on $60^{\text {th }}$ day and $90^{\text {th }}$ day was also recorded with reference to the control group. The Squalene alone treated rats showed significant effect on increased body weights on selected days of experiment when compare to control group. On the contrary, the protective group rats (ADI+SQT), which were treated with squalene for 60 and 90 days exhibited improved body weights when compared to Alzheimer's Diseased model group.

In parallel to these parameters, the organ index of selected organs such as Brain, Liver, Kidney and Spleen, also showed significant weakening in the AD-model group when compared to that of squalene alone treated group. The modulatory effects of squalene on spatial memory (wherein the escape latency was taken as an index of impairment of cognitive function) were studied by Morris water maze experiment. The results shows that, Squalene alone treated rats have showed better escape latency on selected days of experiment, when compared to control rats. On the contrary, the rats treated with alone D-Galactose showed a significant enhancement in the escape latency time on $60^{\text {th }}$ day and $90^{\text {th }}$ day. Interestingly, the protective group of rats (ADI+SQT), showed better recovery tendency with reduced latency on $60^{\text {th }}$ day and $90^{\text {th }}$ day treated rats and it was almost enhanced than that of the control group rats. 
Based on these findings along with the previous research support, it can be suggested that the marine bioactive compound squalene selected for present study, play an important role in treatment of one of the cognitive disorders viz. Alzheimer's Disease. From my observations as detailed above, it was concluded that Squalene showed positive effects on total body weight, Learning and Memory (Cognitive skills) in AD-induced rats.

\section{CONCLUSION}

My observations on protective group revealed significant differences between the control and $A D$-model rats in Morris water maze test, suggesting that oral administration of squalene might ameliorate memory impairment and behavioral changes in AD model rats. Our research results derive strong support from earlier reports where significant improvement in memory loss in mouse caused by scopolamine and D- Galactose. From the results obtained in the present investigation, it was obvious that the squalene showed positive effects on morphological and behavioral aspects wherein D-Galactose injection impaired the learning and memory performance, while though oral administration of squalene significantly reversed the memory impairments and behavioral activity in $A D$ induced rats.

\section{REFERENCES}

1. Francis PT, Palmer AM, Snape M, Wilcock GK, The cholinergic hypothesis of Alzheimer's disease: a review of progress, Journal of Neurol. Neurosurg. Psychiatry. 1999; 66: 137-147.

2. Geldmacher DS, Whitehouse PJ, Vascular Dementia and Alzheimer's Disease: Is There a Difference? A Comparison of Symptoms by Disease Duration, Neurology. 1997; 48: S2-S9.

3. Boustani M, Peterson B, Hanson L, Screening for dementia in primary care: a summary of the evidence for the U.S. Preventive Services Task Force. Ann. Int. Med. 2003; 138:927937.

4. Desgranges B, Baron JC, Sayette V, Petit-Taboue MC, Benali $\mathrm{K}$, Landeau $\mathrm{B}$, Lechevalier B, Eustache $\mathrm{F}$, Working memory and FDG-PET dissociate early and late onset Alzheimer disease patients Brain, 1998; 121: 611-631.

5. Forstl H, Hentschel F, Sattel H, Natural Products and Derivatives Affecting Neurotransmission Relevant to Alzheimer's and Parkinson's Disease, Drug Res. 1995; 45: 394-397.

6. McGuffey EC, Identification of Potential Inhibitors against Acetylcholinesterase Associated With Alzheimer's Diseases: A Molecular Docking Approach, 1997; 37: 347 - 352.

7. Benzi $G$, Moretti $A$, Are reactive oxygen species involved in Alzheimer's disease?, Neuro biol. Aging. 1995; 16: 661-674.

8. Inestrosa NC, Alvare A and Garrido J. In Alzheimer's disease: Biology, Diagnosis and Therapeutics, John Wiley and Sons. London, 1997; 500-510.

9. Smit, A.J, Medicinal and pharmaceutical uses of seaweed natural products, A. review. J. Appl. Phycol. 2004; 16: 245262.
10. Cho S, Kim S-K, Neuro pharmacological properties of marine plants, In Marine Pharmacognosy: Trends and Applications, Taylor \& Francis, 2012; pp. 355-372.

11. Marcus, Traditional morphometrics Proceedings of the Michigan Morphometric Workshop, Special Publication No. 2. (Edited by F.J. Rohlf and F.L.Bookstein). The University of Michigan Museum of Zoology. 1990; 13: 77-122.

12. Zelditch Swiderski Sheets and Fink, Geometric Morphometrics for biologists a primer - Elsevier Academic Press, New York. and London, 2004; p. 437 ISBN 012-77846-08.

13. Vincent Herrel and Irschick, Sexual dimorphism in head shape and diet in the cotton mouth snake (Agkistrodon piscivorus)., J. Zool. 2004; 264: 53-59.

14. Lieberman Sphenoid shortening and the evolution of modern human cranal shape. Nature. 1998; 393: 158-162.

15. Green AJ Mass/length residuals: measures of body condition or generators ofspurious results, Ecology. 2001; 82: 14731483.

16. Klingenberg \& Ekau A combined morphometric and phylogenetic analysis of an ecomorphological trend: pelagization in Antarctic fishes (Perciformes: nototheniidae), Biol J Linnean Soc. 1996; 59: 143-177.

17. Krunk Clutton-Brock Slate Pemberton Brotherstone and Guinness Heritability of fitness in a wild mammal population. Proceedings of the National Academy of Sciences of the United States of America. 2000; 97: 698-703.

18. Ackermann RR, Ontogenetic integration of the homoinoid face, J. Hum. Evol. 2005; Feb; 48(2): 175-97.

19. Jimmy David Donald and Dennis Variability in Body Morphometric Measurement and Their Application in Predicting Live Body Weightof Mubende and Small East African Goat Breed in Uganda, Middle-East J. Sci.Res. 2010; 5 (2): 98-105.

20. Alpak Onar and Mutus, The relationship between morphometric and long bone measurements of the Morkaraman sheep, Turkish J. Vet. Anim. Sci. 2009; 33(3): 199-207.

21. Okoro Ezeokeke Ogundu and Chukudum, Phenotypic correlation of bodyweight and linear body measurement in Chinchilla rabbits (Orycotolagus cuniculus). J. Agri. Biotech. Sustain. Develop. 2010; 2(2): 27-29.

22. Brandeis Brandys and Yehuda, The use of the Morris water maze inthe study of memory and learning, Int. J. Neurosci. 1989; 48: 29-69.

23. Hooge and De Deyn, Applications of the Morris water maze in the studyof learning and memory, Brain Res. Rev. 2001; 36: 60-90.

24. McNamara and Skelton, The neuro pharmacological and neurochemical basis of place learning in the Morris water maze, Brain Res. Rev. 1993; 18: 33-49.

25. Moser Krobert Moser and Morris, Impaired spatial learning after saturation of long term potentiation, Science. 1993; 281: 2038-2042.

26. Paulus Geyer Gold and Mandell, Application of entropy measures derived from the ergodic theory of dynamical 
systems to rat locomotor behaviour, Proc. Natl. Acad. Sci. US A. 87: 723-727.

27. Paulus Dulawa Ralph and Geyer, Behavioral organization is independent of locomotor activity in 129 and C57 mouse strains, Brain Res. 1999; 835: 27- 36.

28. Krunk Clutton-Brock Slate Pemberton Brother stone and Guinness Heritability of fitness in a wild mammal population, Proceedings of the National Academy of Sciences of the United States of America. 2000; 97: 698-703.

29. Bannerman Rawlins Mchugh Deacon Yee Bast Zhang Pothuizen and Feldon Regional dissociations within the hippocampus memory and anxiety, Neuroscience \& Biobehavioral Reviews. 2004; 28(3): 273-283.

30. Mayer, Rodríguez, Berlinck, Fusetani, Marine pharmacology in Marine compounds with antibacterial, anticoagulant, antifungal, anti-inflammatory, antimalarial, antiprotozoal, antituberculosis, and antiviral activities affecting the immune and nervous system, and other miscellaneous mechanisms of action. Comp. Biochem. Physiol. C Pharmacol. Toxicol. Endocrinol. 2007; 153: 191-222.

31. Seubert, Drugs in space Pharmacokinetics and pharmaco dynamics in astronauts, Eur. J. Pharm. Sci. 2008; 109S: S2-S8.

32. Cui Zuo Zhang Li Hu Long Packer and Liu Chronic systemic DGalactose exposure induces memory loss neurodegeneration and oxidative damage in mice protective effects of alpha-lipoic acid, J. Neuros. Res. 2006; 83: 1584-1590.

33. Lei Hua Xiao Ding Han and Hu, Impairments of astrocytes are involved in the D-Galactose induced brain ageing, Biochem. Biophys. Res. Commun. 2008; 369: 1082-1087.

34. Lyte, Microbial endocrinology and nutrition a perspective on new mechanism by which diet can influence Gut-brain communication. Pharma.Nutrition, 2013; 1: 35-39.

Source of Support: The author(s) received no financial support for the research, authorship, and/or publication of this article.

Conflict of Interest: The author(s) declared no potential conflicts of interest with respect to the research, authorship, and/or publication of this article.

For any question relates to this article, please reach us at: editor@globalresearchonline.net New manuscripts for publication can be submitted at: submit@globalresearchonline.net and submit_ijpsrr@rediffmail.com 